listed in an appendix to the report. The Commission, together with the ten Australian universities, constitutes the corporate membership of the Australian Institute of Nuclear Science and Engineering, which is governed by the Institute Council consisting of one representative from each of the universities and four from the Commission. All member universities are engaged in training nuclear scientists and engineers and in related research. 112 projects were supported by research and training grants of the Institute, and the expenditure amounted to about $£ A 100,000$. Plasma physics, in particular, received special support. An informal conference on plasma physics was held during November 1963, and the research effort at three universities was assisted by providing on loan a special high-speed camera capable of photographing the formation and decay of plasmas. Two other informal specialists conferences were held at Lucas Heights under the auspices of the Institute-a "Heat Transfer and Fluid Flow" conference during August 1963, and a "Radiation Chemistry" conference during October 1963.

In conjunction with the University of New South Wales, the Commission is to establish an Australian School of Nuclear Technology with headquarters at the Lucas Heights Research Establishment. The facilities of both the Research Establishment and the University will be available to the School. The aim is to promote formal training and education in nuclear technology; and fulltime courses of varying length in the science and technology of nuclear reactors, the production and application of radiosotopes, radiological safety and health physics, etc., will be open to students from Australia and overseas.

S. Weintroub

\title{
BRITISH CHEMICAL REFERENCE SUBSTANCES
}

$\mathrm{I}_{\mathrm{P}}^{\mathrm{N}}$ late 1963, the General Medical Council and the Pharmaceutical Society of Great Britain agreed to set up a joint authority to prepare and distribute chemical reference substances needed to carry out certain tests and assays described in the British Pharmacopoeia, the British Pharmaceutical Codex and the British Veterinary Codex. The Joint Committee held its first meeting in March 1964, and established a number of panels. Each panel was charged with the task of establishing one or more of these reference substances, and, since these substances might be of value for other purposes, the panels were asked, should it prove impracticable to obtain absolute purity, to ascertain so far as possible the amounts of all impurities.

The first two "British Chemical Reference Substances" have now been made available: digoxin and 2-t-butyl-4methoxyphenol (the most active isomer present in butylated hydroxyanisole); these are required for the Addendum 1964 to the British Pharmacopoeia 1963, which became official as from June 1, 1965. The reports to the Joint Committee of the panel responsible on the preparation and purity of these substances have now been published.

The digoxin reference substance is required in the assay of digoxin and of its two preparations, the injection and the tablets, and for purposes of comparison (in place of the previously used authentic specimen) in the infra-red identification test. From its examination of the reference substance, the panel concluded that the substance is at least 99.7 per cont pure, containing not more than a total of $0 \cdot 3$ per cent of gitoxin, acetyldigoxin, digoxigenin and digitoxin.

The 2-t-butyl-4-methoxyphenol reference substance is required for the assay of butylated hydroxyanisole and in the infra-red identification test. In this case, a purity of at least 99.85 per cent has been achieved, the balance being made up of very small amounts of $3,3^{\prime}$-di-( $t$-butyl)$2,2^{\prime}$-dihydroxy-5,5'-dimethoxybiphenyl (bis-BHA), 2,5di-(t-butyl)-4-methoxyphenol, 4-methoxyphenol and a trace of an unidentified impurity. As well as its pharmaceutical uses, butylated hydroxyanisole has extensive usage in the food industry as an anti-oxidant in oils and fats, and the establishment of this reference substance will be welcomed in fields outside of pharmacy.

Samples of these reference substances are distributed by the Pharmaceutical Society and are available on application to the Assistant Director, Department of Pharmaceutical Sciences, 17 Bloomsbury Square, London, W.C.1, at a cost of $£ 410 \mathrm{~s}$. for $0.3 \mathrm{~g}$ of the digoxin, and $£ 3$ for $0.2 \mathrm{~g}$ of the 2-t-butyl-4-methoxyphenol. Copies of the panel's reports can be obtained from either of the joint secretaries, Mr. T. C. Denston, 44 Hallam Street, London, W.1, and Dr. K. R. Capper, 17 Bloomsbury Square, London, W.C.1.

Because there may be some confusion between "British Chemical Reference Substances" and "Authentic Specimens", both of which are distributed by the Pharmaceutical Society, it is appropriate to explain that the reference substances are samples which have been purified so far as is practically and economically feasible, any remaining impurities having been identified and a limit set on their presence. They are used in assay procedures and to serve as the reference material in tests used to limit the presence of certain impurities in pharmacopoeial and Codex substances. Authentic specimens, on the other hand, are only tested samples of good quality commercial material which are needed for certain tests, notably infra-red identification tests, for which a comparison material having the purity of a reference substance is not essential.

\section{PESTICIDES IN THE ENVIRONMENT}

\begin{abstract}
$\Delta \mathrm{N}$ advanced study institute on "Pesticides in the Environment and their Effects on Wildlife", sponsored by the North Atlantic Treaty Organization, was held at Monks Wood Experimentsl Station during July 1-14.

The main purpose of the Institute was to enable those working on the effects of pesticides on wildlife to exchange ideas and to discuss future research. Thirty-four papers were read, and dealt with the background of the wildlife problem and with field and laboratory studies of the effects of pesticides in terrestrial, freshwater and marine environments. Seventy-one scientists from Government
\end{abstract}

and university laboratories attended the moeting, including chemists, toxicologists and zoologists of eleven nationalities.

The papers and discussions showed that pesticide residues have been detected in a wide spectrum of physical and biological samples from diverse environments, indicating that contamination is widespread. In some instances, harmful effects on wildlife populations were clearly demonstrated, but more frequently the effects of residues are unknown.

It was concluded that in order to understand the effects of pesticides more fully, there was need for more work, 
including: routine collection of data; experimental research; use of present knowledge; and dissemination of information. Details are as follows:

Routine collection of data. Carefully designed surveys are needed to obtain valid estimates of animal populations to assess effects of changing environmental conditions. Furthermore, it is necessary to measure the accumulation of chemical residues in many physical and biological components of the environment to assess the present and future levels of contamination. Existing studies of residues in Belgium, Canada, Eire, France, the Netherlands, Sweden, the United Kingdom and the United States provide the basis for further research of this kind. Special emphasis should be placed on persistent compounds, and on aquatic species which seem to be especially valuable as indicator organisms. Multiple-detection methods with associated techniques for confirmation of identity should be used wherever possible. Detailed information concerning the total quantity of pesticide used in different countries must be obtained to understand residue data properly, and to predict future trends.

Experimental research. There is a need for developing and standardizing analytical procedures, censusing methods and other techniques. Investigators should pay full attention to the use of critical and confirmatory techniques which have already been worked out, and to the statistical treatment of accumulated data. More work is required on pesticides other than organochlorine compounds. In particular, improved methods of chemical analysis for organophosphorus pesticides and their metabolites should be investigated. The dynamics of pesticides in different environments need to be investigated more thoroughly, including decomposition, physical and biological dispersal and accumulation. Additional investigations are required to resolve the difficulties in using results obtained from laboratory studies to assess possible effects on populations in the field. Long-term field studies are particularly necessary for assessing the effects of persistent chemical compounds and their metabolites.

Use of present knowledge. It is necessary to ensure that the great body of existing data be applied, starting at the stage of introduction of a now pesticide, and in considering the introduction of extensive control programmes. Special consideration should also be given to raro species and those of restricted range and special vulnerability.

Dissemination of information. To implement the development of research outlined above, it was hoped that members of the Conference would continue to exchange information, and that international meetings of a similar kind to this Advanced Study Institute would be held at regular intervals. An annual list of current research projects would be particularly valuable.

\title{
NOCTILUCENT CLOUDS OVER NORTH AMERICA
}

\author{
BY BENSON FOGLE \\ Geophysical Institute, University of Alaska College, Alaska
}

$\Gamma^{\mathrm{N}}$ N 1962, when the work reported here began, only one recorded sighting of noctilucent clouds from North America was known. This was the observation reported. by Vestine in 1934 (ref. 1). The scarcity of sightings from North America led to the belief that noctilucent clouds did not occur here as frequently as over Europe and the U.S.S.R., where hundreds of such observations have been made during the past eighty years.

A careful literature search made in 1962 uncovered eleven additional records of North American sightings of noctilucent clouds, and an observation programme conducted at College, Alaska, during the summer of 1962 resulted in five more sightings. On the basis of these findings it was concluded ${ }^{2}$ that noctilucent clouds occurred over North America more frequently than previously supposed, and that the scarcity of recorded observations was probably due to the lack of informed and interested observers.

To investigate the apparent frequency of occurrence, spatial extent and lifetime of noctilucent clouds over North America, an extensive network of noctilucent cloud obsorving stations was established in 1963 over Alaska and Canada which in 1964 was extended to Greenland and Iceland. Co-operation in the set-up of this network of stations was given by the Canadian Department of Transport, the Icelandic Meteorological Service, the U.S. Weather Bureau, the U.S. Federal Aviation Agency and the U.S. Air Force Weather Squadrons. Fig. I shows the locations of the stations participating in this programme. A Noctilucent Cloud Observation Manual ${ }^{3}$ was prepared. and issued to all participating stations to acquaint the observers with noctilucent clouds. During the summer of 1963 , only 33 Alaskan stations and 15 stations in western Canada took part in the programme. This past summer (1964) all the stations shown in Fig. 1 took part, as well as the crews of the Pan American World Airways and Alaska Airlines aircraft flying the Fairbanks-Scattle route.

During 1963, with 48 stations participating, 25 displays of noctilucent clouds were sighted over North America.
During 1964, with 88 stations participating, 57 displays were sighted. These numbers represent reliable sightings. A number of additional reports had to be discarded because of insufficient evidence of a definite display. A complete listing of the nights of the 99 displays of noctilucent clouds reported over North America to date is given in Table 1. It also gives the number and latitude and longitude range of the stations which reported noctilucent clouds on these nights. The low-latitude, artificially produced noctilucent clouds reported by Meinel $^{4}$ are not included in Table 1. The date of the display, given by a single number, refers to the night beginning on that date and ending on the following one. The observations listed in Table 1 are presented in Fig. 2 in the form of a histogram and a smoothed curve. The

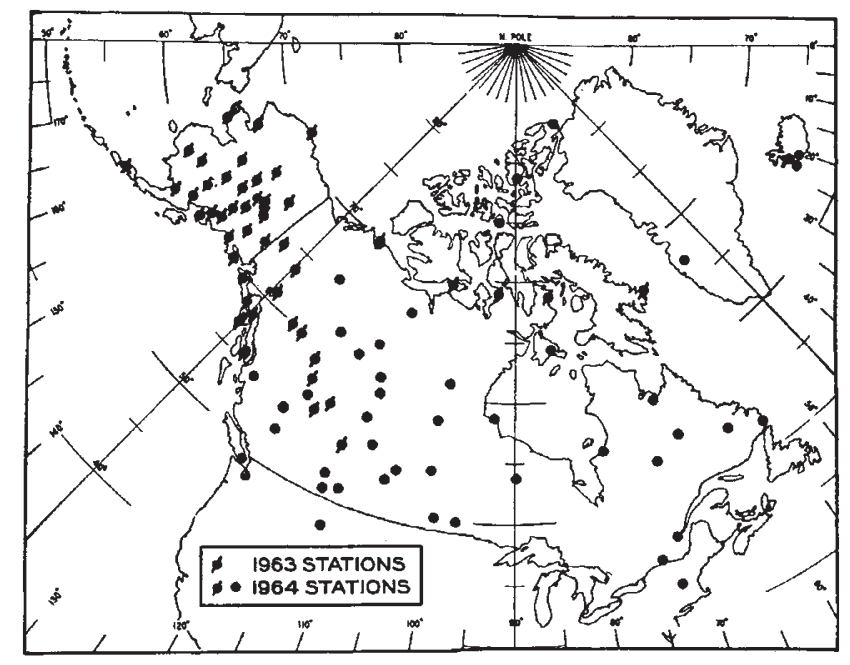

Fig. 1. Network of noctilucent cloud-observing stations over North America, Greenland and Iceland 